\title{
Preemptive pain-management program is associated with reduction of opioid prescriptions after benign minimally invasive foregut surgery
}

\author{
Min P. Kim, MD, FACS, ${ }^{\text {a,b }}$ Carla Godoy, ${ }^{a}$ Duc T. Nguyen, MD, PhD, \\ Leonora M. Meisenbach, DNP, RN, ACNP-BC, ${ }^{\text {a }}$ Ray Chihara, MD, PhD, \\ Edward Y. Chan, MD, FACS, ${ }^{a, b}$ and Edward A. Graviss, PhD, MPH, FIDSA
}

\section{ABSTRACT}

Objective: The opioid crisis is partly due to opioids prescribed after elective surgery. We sought to determine if a preemptive pain-management program would be associated with opioid-free discharge after benign foregut surgery.

Methods: A retrospective case-control study of prospectively collected data was conducted at a single institution of patients who underwent elective minimally invasive benign foregut surgery. We compared the outcomes among patients who were managed with standard care (control), enhanced recovery after surgery alone, or a preemptive pain-management program with enhanced recovery after surgery.

Results: Among 414 patients, there were significantly fewer opioid medication prescriptions at discharge $(9.6 \%$ vs $85.2 \%$ vs $87 \%, P<.001)$ and fewer postoperative complications $(3.2 \%$ vs $14.8 \%$ vs $15.1 \%, P=.004)$ in the preemptive pain-management group $(\mathrm{n}=94)$, enhanced recovery after surgery alone $(\mathrm{n}=81)$, and the control group $(\mathrm{n}=239)$, respectively. Multivariable logistic regression analysis showed that the preemptive pain-management program was a factor associated with a decrease in opioid medication prescriptions at discharge (odds ratio, 0.01; 95\% confidence interval, 0.01-0.03; $P<.001$ ), as well as a decrease in complications after surgery (odds ratio, $0.22 ; 95 \%$ confidence interval, $0.06-0.79 ; P=.02$ ). Moreover, in the preemptive pain-management group, average self-reported pain level in a subset of patients at 30 days after surgery was $0.9 \pm 1.4$ on a 0 - to 10 -point pain scale.

Conclusions: The preemptive pain-management program was associated with opioid-free discharge after minimally invasive foregut surgery. This study provides a strategy to reduce opioid prescriptions after foregut surgery and, if implemented nationally, could decrease the amount of opioids used in the community. (J Thorac Cardiovasc Surg 2020;159:734-44)

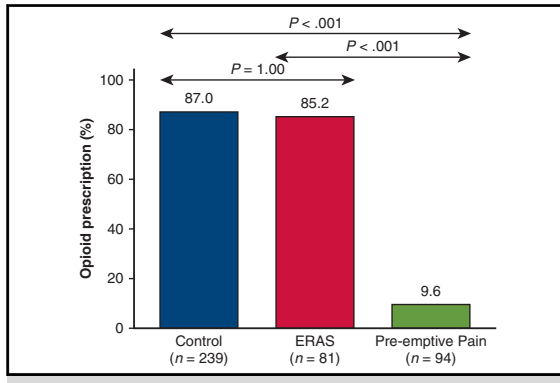

Preemptive pain-control program decreases postoperative opioid prescription.

\section{Central Message}

A preemptive pain-management program is associated with opioid-free discharge after foregut surgery.

\section{Perspective}

An ERAS program alone has not decreased the number of opioid prescriptions written after surgery. The addition of a preemptive painmanagement program to ERAS with patient education and nonopioid around-the-clock pain management was associated with a significant decrease in the number of opioid prescriptions after surgery.

See Commentaries on pages 745 and 747.
From the a Division of Thoracic Surgery, Department of Surgery, ${ }^{\mathrm{b}}$ Department of Surgery, Weill Cornell Medical College, and ${ }^{\mathrm{c}}$ Department of Pathology and Genomic Medicine, Houston Methodist Hospital, Houston, Tex.

Date and Number of Institutional Review Board Approval: January 19, 2018. Pro00009372

Read at the 45th Annual Meeting of the Western Thoracic Surgical Association, Olympic Valley, California, June 26-29, 2019.

Received for publication Feb 1, 2019; revisions received May 30, 2019; accepted for publication June 1, 2019; available ahead of print Sept 30, 2019.

Address for reprints: Min P. Kim, MD, FACS, 6550 Fannin St, Suite 1661, Houston, TX 77030 (E-mail: mpkim@ @oustonmethodist.org).

$0022-5223 / \$ 36.00$

Copyright (c) 2019 by The American Association for Thoracic Surgery

https://doi.org/10.1016/j.jtcvs.2019.06.056
Prescription opioid medications led to an estimated 17,087 deaths in 2016. ${ }^{1}$ A portion of these deaths may be due to the availability of opioids after elective surgery because opioids are commonly prescribed upon discharge. Studies have shown that approximately $3 \%$ to $10 \%$ of opioid-naïve surgical patients will continue to take opioids 1 year after

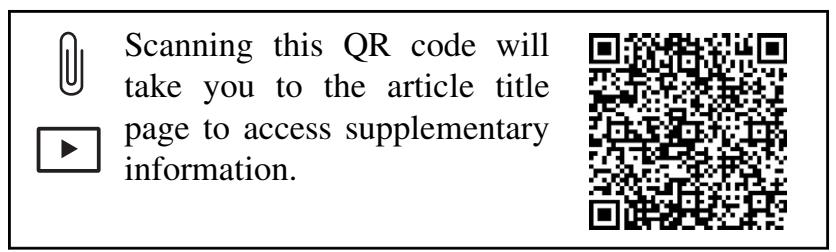



Abbreviations and Acronyms
ASA $=$ American Society of Anesthesiologists
$\mathrm{CI}=$ confidence interval
ERAS $=$ enhanced recovery after surgery
IV $=$ intravenous
$\mathrm{OR}=$ odds ratio

To change routine default prescribing of opioid pain medications, we developed a postoperative preemptive pain-management program at our institution to change our programmatic culture to use nonopioid pain medications at discharge. The program includes preoperative education of patients and default use of nonopioid pain management after surgery. In this study, we evaluated the efficacy of our preemptive pain-management program and determined factors associated with the ability to send patients home without opioid prescriptions. In addition, we determined the impact of the program on postsurgical outcomes and pain scores 30 days after surgery.

\section{MATERIALS AND METHODS}

The Institutional Review Board at Houston Methodist Hospital approved this study, and consent for research was waived (Pro00009372). We reviewed all patients who underwent foregut surgery at Houston Methodist Hospital by surgeons in the Division of Thoracic Surgery from 2012 to 2018. During this time period, there was a gradual implementation of the ERAS program. Some parts of the ERAS program were implemented in 2014 , when we implemented the initial parts of the program that could be controlled by the surgical team. In 2016, we were able to fully implement all components of the ERAS program, ${ }^{5,6}$ and in 2017 we implemented the preemptive pain-management program (Table 1 and Video 1). The perioperative preemptive pain control was already part of our ERAS protocol, but 2 changes were made postoperatively for the preemptive painmanagement program: enhanced patient education and discharge with nonopioid pain medication by default.

Our enhanced patient education efforts were directed at partnering with the patient to align expectations for pain management postoperatively and at discharge, while explicitly addressing our reasoning behind discharging the patient home with nonopioid pain medication. Although individual conversations varied between surgeons and patients, a typical discussion might include the following: "It is important for us that you have adequate pain control after surgery because it has a major impact on your recovery. In the past, we would recommend that you take medication after you start feeling pain, which would typically require opioids to control sufficiently. Our new protocol involves preemptively placing a long-acting local anesthetic at each incision, along with maintaining scheduled doses of your oral pain medication, so that we can proactively treat your pain before it becomes severe. This will allow us to stay ahead of your pain with a combination of nonopioid medications so we can minimize your pain during your recovery without having to give you narcotics." Our default pain medications at discharge are acetaminophen $1 \mathrm{~g}$ orally every 8 hours for 5 days with or without naproxen sodium $220 \mathrm{mg}$ orally every 12 hours for 3 days depending on the patient's age and renal function.

This regimen was changed if the initial set of medications (Table 1) did not manage the patient's pain in the hospital. While the patient was in the hospital, we escalated the medications as follows: We would start with gabapentin $300 \mathrm{mg}$ orally every 8 hours as needed, then cyclobenzaprine $5 \mathrm{mg}$ orally every 8 hours as needed, then tramadol $50 \mathrm{mg}$ orally every 6 hours as needed, then hydromorphone $0.1 \mathrm{mg}$ IV $\times 1$ every 1 hour $\times 2$ doses, and finally a hydromorphone patient-controlled analgesic. Patients were discharged home with appropriate per os pain medication. At home, patients were asked to call our office if the per os pain regimen was not enough to control pain.

In this analysis, we included all patients who underwent elective benign minimally invasive foregut surgery during this time period. We excluded any patients who had an urgent or emergency operation. We also excluded those patients who had open surgery, repair of a tracheoesophageal fistula, or supercharged pedicled jejunal interposition in roux-en-y went home with less narcotics. 
TABLE 1. Pain-control regimen during different time periods

\begin{tabular}{llll}
\hline & \multicolumn{1}{c}{ Control } & \multicolumn{1}{c}{ ERAS } & Preemptive pain \\
\hline $\begin{array}{c}\text { Preoperative } \\
\text { pain regimen* }\end{array}$ & None & Tramadol & Tramadol $50 \mathrm{mg}$ PO $\times 1$ \\
\hline $\begin{array}{l}\text { Intraoperative } \\
\text { pain regimen }\end{array}$ & None & Gabapentin & Gabapentin $300 \mathrm{mg} \mathrm{PO} \times 1$ \\
\hline $\begin{array}{c}\text { Postoperative } \\
\text { pain regimen }\end{array}$ & $\begin{array}{c}\text { Acetaminophen } \\
\text { hydromorphone }\end{array}$ & Ketorolac $\dagger$ & Acetaminophen $1 \mathrm{~g} \mathrm{IV} \times 1$ \\
\hline $\begin{array}{c}\text { hefault discharge } \\
\text { medication }\end{array}$ & $\begin{array}{l}\text { Bupivacaine Liposome } \\
\text { Acetaminophen/ } \\
\text { hydrocodone }\end{array}$ & Acetaminophen ATC & Ketorolac $15 \mathrm{mg} \mathrm{IV} \times 1 \dagger$ \\
\hline
\end{tabular}

Naproxen sodium $220 \mathrm{mg}$ PO every $12 \mathrm{~h} \times 3 \mathrm{~d}$ ATC $\dagger$

$E R A S$, Enhanced recovery after surgery; $P O$, per os; $I V$, intravenous; $P C A$, patient-controlled analgesic; $A T C$, around the clock. *Patients with achalasia and large type III hiatal hernia did not receive preoperative PO pain medication. †Patients were given this medication if the creatinine level is less than 1 and the patient's age is less than 75 years. The other PO option was ibuprofen $400 \mathrm{mg}$ PO every 8 hours.

esophagojejunostomy for esophageal reconstruction, a total gastrectomy, or esophagectomy. Demographics, comorbidities, operation type, surgeon, pathology, morbidity, mortality, and length of stay for patients during this time period were obtained from a prospectively collected Society of Thoracic Surgeons database and the electronic health record. We also obtained information regarding the pain medications that patients were given

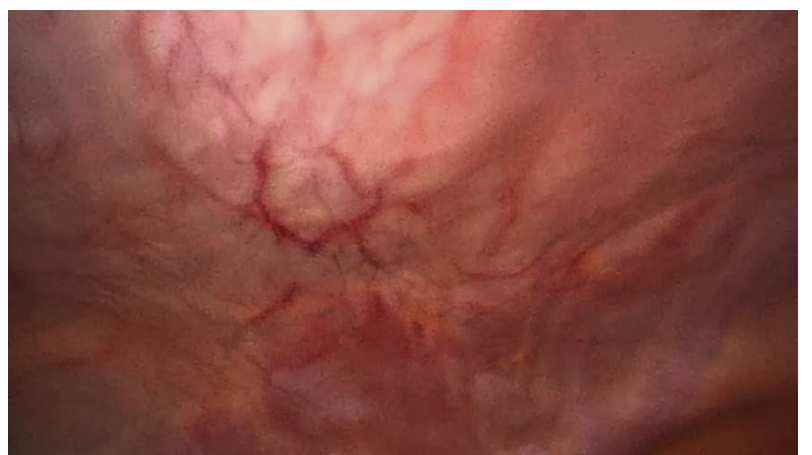

VIDEO 1. Video recording of injection of bupivacaine liposome injectable suspension during port placement; $2 \mathrm{~mL}$ of bupivacaine liposome injectable suspension is placed in the subcutaneous space of the left mid port site (not shown). We then use a 5-mm optical trocar to enter the abdominal cavity and insufflate the abdomen. Next, $5 \mathrm{~mL}$ of bupivacaine liposome injectable suspension is placed in the right mid quadrant port site with local in the preperitoneal space and the muscle layers above with an 8-mm robot port placed in the site. We then place the camera in the right mid quadrant port and place $5 \mathrm{~mL}$ of bupivacaine liposome injectable suspension in the left lateral port site and subsequently place the $8-\mathrm{mm}$ port. The $5-\mathrm{mm}$ optical trocar is removed, and $3 \mathrm{~mL}$ of bupivacaine liposome injectable suspension is placed in that site, and an 8 -mm robot port is placed in the left mid port site. Finally, a camera is placed in the left lateral port and the final $5 \mathrm{~mL}$ of the bupivacaine liposome injectable suspension is placed in the mid-line port site approximately $13 \mathrm{~cm}$ from the xyphoid process, and an $8-\mathrm{mm}$ robot port is placed. Video available at: https://www.jtcvs.org/article/S0022-5223(19)31351-0/ fulltext. at the time of discharge. We categorized these medications as opioids or nonopioid medications. After the full implementation of the preemptive pain-management program, we recorded the number of patients who called the office within 30 days after the operation for opioid pain medication and the patients' self-reported pain level (scale 0-10) on follow-up at approximately 30 days.

Continuous variables were evaluated for their normality using the histogram plotting method. Demographic and clinical data were reported as frequencies and proportions for categoric variables and as medians and interquartile ranges or means ( \pm standard deviation) for continuous variables as appropriate. Differences between groups were compared using the chi-square or Fisher-Freeman-Halton exact tests (for comparisons that have cell counts $<5$ ) for categoric variables and an unpaired $t$ test (if normally distributed) or Kruskal-Wallis test (if not normally distributed) for continuous variables as appropriate. Bonferroni corrections were used to adjust for multiple comparisons. Univariable logistic regression analysis and multivariable logistic regression modeling were performed to determine the characteristics associated with the outcomes. Variables that were used in the univariable analysis included demographics, ethnicity, body mass index, comorbidities, medical history, smoking, Zubrod score, opioid use before surgery, indication, reoperation, primary procedure, robotic technology, and surgeon. Variables with a $P$ value of less than .2 in the univariable analysis or considered clinically significant (opioids before surgery, gender and surgeon) were investigated further by multivariable logistic regression modeling. The likelihood test was used to reduce the model subsets. The best model was selected on the basis of the smallest Bayesian information criterion. All analyses were performed using Stata version 15.1 (StataCorp LLC, College Station, Tex).

\section{RESULTS}

A total of 414 patients met the inclusion and exclusion criteria from 2012 to 2018 . There were 94 patients in the preemptive pain-management group with ERAS, 81 patients in the ERAS-only group, and 239 patients in the control group. There was no significant difference among groups in age, gender, body mass index, cigarette smoking, comorbidities, opioid use before surgery, and reoperation (Table 2). However, there were significantly more patients 
TABLE 2. Patient and procedural characteristics

\begin{tabular}{|c|c|c|c|c|c|}
\hline Characteristics & $\begin{array}{c}\text { Total } \\
(\mathbf{N}=\mathbf{4 1 4})\end{array}$ & $\begin{array}{c}\text { Control } \\
(\mathbf{n}=\mathbf{2 3 9})\end{array}$ & $\begin{array}{c}\text { ERAS } \\
(\mathbf{n}=\mathbf{8 1})\end{array}$ & $\frac{\text { Preemptive pain }}{(\mathbf{n}=94)}$ & Overall $P$ value \\
\hline Age $(y)$ & $60.5(51.0-72.0)$ & $61.0(52.0-71.0)$ & $56.0(43.0-68.0)$ & $62.5(52.0-72.0)$ & .053 \\
\hline Male & $146(35.3)$ & $87(36.4)$ & $32(39.5)$ & $27(28.7)$ & .28 \\
\hline White & $335(80.9)$ & $183(76.6)$ & 67 (82.7) & $85(90.4)$ & .01 \\
\hline Body mass index, median (IQR) & $29.0(25.5-33.1)$ & $28.9(25.2-32.8)$ & $28.9(26.1-33.3)$ & $30.1(26.2-34.3)$ & .28 \\
\hline \multicolumn{6}{|l|}{ Comorbidities } \\
\hline Hypertension & $226(54.6)$ & $136(56.9)$ & $42(51.9)$ & $48(51.1)$ & .53 \\
\hline Diabetes & $54(13.0)$ & $36(15.1)$ & 7 (8.6) & $11(11.7)$ & .33 \\
\hline Coronary artery disease & $50(12.1)$ & $34(14.2)$ & $7(8.6)$ & $9(9.6)$ & .34 \\
\hline Chronic obstructive pulmonary disease & $39(9.4)$ & $27(11.3)$ & $7(8.6)$ & $5(5.3)$ & .24 \\
\hline Cerebrovascular history & & & & & .15 \\
\hline Transient ischemic attack & $15(3.6)$ & $11(4.6)$ & $2(2.5)$ & $2(2.1)$ & \\
\hline Cerebrovascular accident & $11(2.7)$ & $4(1.7)$ & $1(1.2)$ & $6(6.4)$ & \\
\hline Prior cardiothoracic surgery & $22(5.3)$ & $14(5.9)$ & $5(6.2)$ & $3(3.2)$ & .63 \\
\hline Cigarette smoking (past or current) & $134(32.4)$ & $86(36.0)$ & $21(25.9)$ & $27(28.7)$ & .18 \\
\hline Zubrod score & & & & & .21 \\
\hline 1 & $18(4.3)$ & $15(6.3)$ & $0(0.0)$ & $3(3.2)$ & \\
\hline 2 & $373(90.1)$ & $209(87.4)$ & $78(96.3)$ & $86(91.5)$ & \\
\hline 3 & $5(1.2)$ & $4(1.7)$ & $0(0.0)$ & $1(1.1)$ & \\
\hline 4 & $18(4.3)$ & $11(4.6)$ & $3(3.7)$ & $4(4.3)$ & \\
\hline Opioid use before surgery & $32(7.7)$ & $15(6.3)$ & $5(6.2)$ & $12(12.8)$ & .14 \\
\hline Indication & & & & & $<.001$ \\
\hline GERD & $46(11.1)$ & $39(16.3)$ & $6(7.4)$ & $1(1.1)$ & \\
\hline Achalasia & $71(17.1)$ & $49(20.5)$ & $9(11.1)$ & $13(13.8)$ & \\
\hline Hiatal hernia & $297(71.7)$ & $151(63.2)$ & $66(81.5)$ & $80(85.1)$ & \\
\hline Reoperation & $56(13.5)$ & $25(10.5)$ & $13(16.0)$ & $18(19.1)$ & .08 \\
\hline Primary procedure & & & & & $<.001$ \\
\hline Fundoplication & $46(11.1)$ & $39(16.3)$ & $6(7.4)$ & $1(1.1)$ & \\
\hline Heller myotomy & $71(17.1)$ & $49(20.5)$ & $9(11.1)$ & $13(13.8)$ & \\
\hline Hiatal hernia repair without mesh & $290(70.0)$ & $147(61.5)$ & $64(79.0)$ & $79(84.0)$ & \\
\hline Hiatal hernia repair with mesh & $7(1.7)$ & $4(1.7)$ & $2(2.5)$ & $1(1.1)$ & \\
\hline Robotic technology assisted & & & & & $<.001$ \\
\hline Laparoscopic & $204(49.3)$ & $195(81.6)$ & $9(11.1)$ & $0(0.0)$ & \\
\hline Robot Si & $21(5.1)$ & $21(8.8)$ & $0(0.0)$ & $0(0.0)$ & \\
\hline Robot Xi & 189 (45.7) & $23(9.6)$ & $72(88.9)$ & $94(100.0)$ & \\
\hline Surgeon & & & & & $<.001$ \\
\hline Surgeon 1 & $23(5.6)$ & $23(9.6)$ & $0(0.0)$ & $0(0.0)$ & \\
\hline Surgeon 2 & $304(73.4)$ & $171(71.5)$ & $65(80.2)$ & $68(72.3)$ & \\
\hline Surgeon 3 & $43(10.4)$ & $37(15.5)$ & $6(7.4)$ & $0(0.0)$ & \\
\hline Surgeon 4 & 44 (10.6) & $8(3.3)$ & $10(12.3)$ & $26(27.7)$ & \\
\hline
\end{tabular}

Values are in frequency and proportion unless otherwise indicated. Differences across groups were compared using the chi-square or Fisher-Freeman-Halton exact tests (for comparisons that have cell counts $<5$ ) for categoric variables and unpaired $t$ test or Kruskal-Wallis test for continuous variables as appropriate. Other than the gender and white ethnicity, comparisons across groups of other variables were conducted using the Fisher-Freeman-Halton exact tests. ERAS, Enhanced recovery after surgery; $I Q R$, interquartile range; GERD, gastroesophageal reflux disease.

who were white $(90.5 \%$ vs $82.7 \%$ vs $76.6 \%, P=.01)$, had a hiatal hernia as an indication $(85.1 \%$ vs $81.5 \%$ vs $63.2 \%, P<.001)$, had hiatal hernia repair without mesh ( $84 \%$ vs $79 \%$ vs $61.5 \%$ ), and underwent repair with the da Vinci Xi robot (Intuitive, Sunnyvale, Calif) $(100 \%$ vs $88.9 \%$ vs $9.6 \%$ ) in the preemptive pain-management group compared with the ERAS-alone and control groups, respectively (Table 2). The majority of operations were performed by 1 surgeon $(73.4 \%)$, with similar percentages of cases among the 3 periods. During the study time period, 2 surgeons left the practice, which was associated with a significant difference in the surgeon who performed the operations during 3 different time periods $(P<.001)$. 

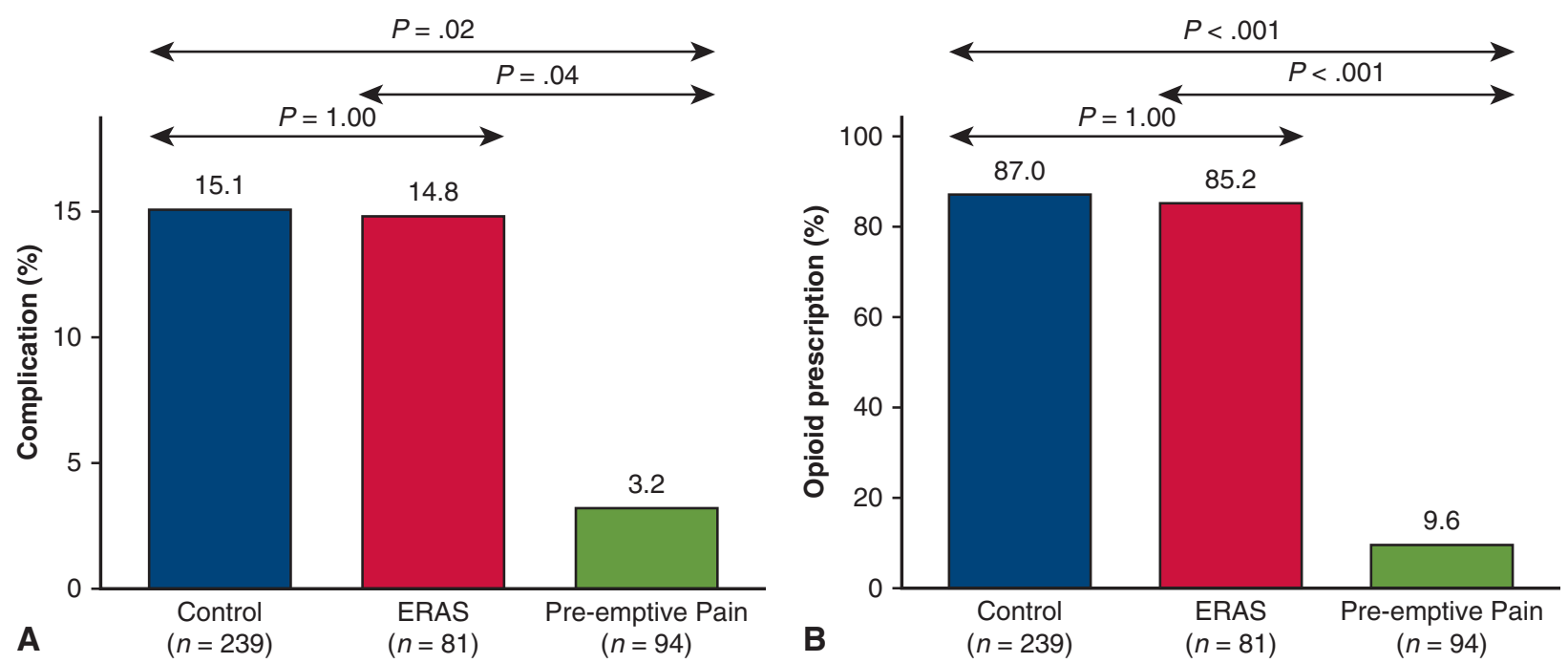

FIGURE 1. Impact of preemptive pain-management program on postoperative complications and discharge home with opioid prescription. Patients in the preemptive pain-management program along with ERAS (preemptive pain) had significantly less postoperative complications ( $3.2 \%$ vs $14.8 \%$ vs $15.1 \%$, $P=.004)(\mathrm{A})$ and fewer opioid discharge pain medications $(9.6 \%$ vs $85.2 \%$ vs $87 \%, P<.001)$ (B) compared with patients who received ERAS or did not receive ERAS or preemptive pain management (control). ERAS, Enhanced recovery after surgery.

Patients who were in the preemptive pain-management group had significantly longer median procedure times compared with the ERAS-only group and control group (203 minutes vs 187 minutes vs 174 minutes, respectively, $P=.002)$. There were significantly fewer complications $(3.2 \%$ vs $14.8 \%$ vs $15.1 \%, P=.004$, Figure $1, A)$, shorter average hospital length of stay $(1.1 \pm 2$ days vs $1.3 \pm 0.7$ days vs $1.8 \pm 1.4$ days, $P<.001$ ) (Table 3 ), and fewer opioid prescriptions after surgery $(9.6 \%$ vs $85.2 \%$ vs $87 \%, P<.001$, Figure $1, B)$ in the preemptive pain-management group compared with the ERAS group and control group, respectively. However, there were no significant differences in the 30-day readmission rate or mortality within 30 days after surgery (Table 3). We performed univariable analysis of the factors that contribute to opioid prescriptions after surgery. We identified preemptive pain control (odds ratio [OR], 0.02; $95 \%$ confidence interval $[\mathrm{CI}], 0.01-0.03 ; P<.001$ ), minimally invasive fundoplication (OR, 2.30; $95 \% \mathrm{CI}$, (1.04-5.08), $P=.04)$, hiatal hernia as an indication (OR, $0.43 ; 95 \%$ CI, $0.19-0.95 ; P=.04)$, the use of robotic technology (OR, $0.71 ; 95 \% \mathrm{CI}, 0.12-0.30 ; P<.001)$, and surgeon (surgeon 1; OR, 3.64; 95\% CI, 1.24-10.64; $P=.02$ ), (surgeon 2; OR, 3.78; 95\% CI, 1.96-7.27; $P<.001$ ), (surgeon 3; OR, 15.49; 95\% CI, 4.69-51.14; $P<.001$ ), (surgeon 4, reference) as significant factors (Table E1). After multivariable logistic regression, we found preemptive pain management was the only significant factor in decreasing opioid prescriptions after surgery $(\mathrm{OR}, 0.01 ; 95 \% \mathrm{CI}, 0.01-0.03 ; P<.001$, Table 4). Univariable analysis was then performed for postoperative events. Analyses found that preemptive pain management (OR, 0.19; 95\% CI, 0.06-0.62; $P=.01$ ), age (OR, 1.04; 95\% CI, 1.01-1.06; $P=.001$ ), BMI (OR, 0.95; 95\% CI, $0.9-1 ; P=.048)$, hypertension (OR, $2.19 ; 95 \% \mathrm{CI}$,
1.16-4.13; $P=.02)$, coronary artery disease (OR, 2.63; 95\% CI, 1.27-5.46; $P=.01$ ), American Society of Anesthesiologist (ASA) classification III (OR, 2.44; 95\% CI, 1.15-5.17; $P=.02$ ), ASA classification IV (OR, 7.75; 95\% CI, 3.02-19.9; $P<.001$ ), and robotic-assisted surgery (OR, $0.49 ; 95 \% \mathrm{CI}, 0.26-0.89 ; P=.02$ ) were significant factors (Table E2). We then performed a multivariable logistic regression and found that preemptive pain management (OR, $0.18 ; 95 \%$ CI, $0.05-0.62 ; P=.02$ ) was associated with a reduction of a postoperative event and that ASA classification IV (OR, 3.36; 95\% CI, 1.01-11.19; $P=.049$ ) was associated with an increase in a postoperative event (Table 5).

In the preemptive pain-management group who went home without opioid prescriptions, none of the patients called the clinic for opioid pain medication after surgery. We obtained self-reported pain level information (1-10 scale) in 55 of 94 patients in the preemptive pain-management group. The average pain level was $0.9 \pm 1.4$ on a 0 to 10 pain scale in the 30 days after surgery.

\section{DISCUSSION}

In this study, evaluated the efficacy of our preemptive pain-management program and determined the factors associated with the ability to send patients home without opioid prescription. In addition, we determined the impact of the program in postsurgical outcomes, the number of patients needing opioids after being discharged home, and the pain score at 30 days after surgery. Our study is based on the fact that the enhanced recovery program has been shown to decrease complications after colorectal surgery ${ }^{13}$ and general surgery ${ }^{14}$; however, it has not been shown to decrease the overall rate of opioid prescriptions at discharge. $^{7}$ The prescription of pain medication at 
TABLE 3. Outcomes of preemptive pain-management program after foregut surgery

\begin{tabular}{|c|c|c|c|c|c|}
\hline Outcome & $\begin{array}{c}\text { Total } \\
(\mathrm{N}=\mathbf{4 1 4})\end{array}$ & $\begin{array}{c}\text { Control } \\
(n=239)\end{array}$ & $\begin{array}{c}\text { ERAS } \\
(n=81)\end{array}$ & $\frac{\text { Preemptive pain }}{(n=94)}$ & Overall $P$ value \\
\hline Unanticipated surgical approach conversion & $1(0.2)$ & $0(0.0)$ & $0(0.0)$ & $1(1.1)$ & .42 \\
\hline Procedure time (min), median (IQR) & $183.2( \pm 69.3)$ & $174.1( \pm 67.7)$ & $187.3( \pm 53.8)$ & $202.8( \pm 80.6)$ & .002 \\
\hline Initial visit to ICU & $11(2.7)$ & $9(3.8)$ & $1(1.2)$ & $1(1.1)$ & .40 \\
\hline Postoperative complication & $51(12.3)$ & $36(15.1)$ & $12(14.8)$ & $3(3.2)$ & .004 \\
\hline Urinary retention & $20(4.8)$ & $15(6.3)$ & $4(4.9)$ & $1(1.1)$ & .11 \\
\hline Discharged with Foley catheter & $7(1.7)$ & $4(1.7)$ & $2(2.5)$ & $1(1.1)$ & .76 \\
\hline Infection requiring IV antibiotics & $7(1.7)$ & $5(2.1)$ & $1(1.2)$ & $1(1.1)$ & .76 \\
\hline Other pulmonary event & $7(1.7)$ & $6(2.5)$ & $1(1.2)$ & $0(0.0)$ & .26 \\
\hline Other GI event & $6(1.4)$ & $2(0.8)$ & $3(3.7)$ & $1(1.1)$ & .16 \\
\hline Unexpected return to operating room & $6(1.4)$ & $6(2.5)$ & $0(0.0)$ & $0(0.0)$ & .17 \\
\hline Postoperative packed red blood cells & $5(1.2)$ & $4(1.7)$ & $1(1.2)$ & $0(0.0)$ & .70 \\
\hline Pneumonia & $4(1.0)$ & $3(1.3)$ & $1(1.2)$ & $0(0.0)$ & .65 \\
\hline Events requiring general anesthesia & $3(0.7)$ & $2(0.8)$ & $1(1.2)$ & $0(0.0)$ & .77 \\
\hline Urinary tract infection & $2(0.5)$ & $2(0.8)$ & $0(0.0)$ & $0(0.0)$ & 1.00 \\
\hline Surgical site infection & $2(0.5)$ & $0(0.0)$ & $1(1.2)$ & $1(1.1)$ & .18 \\
\hline Unexpected admission to ICU & $2(0.5)$ & $2(0.8)$ & $0(0.0)$ & $0(0.0)$ & 1.00 \\
\hline Atelectasis requiring bronchoscopy & $1(0.2)$ & $1(0.4)$ & $0(0.0)$ & $0(0.0)$ & 1.00 \\
\hline Respiratory failure & $1(0.2)$ & $1(0.4)$ & $0(0.0)$ & $0(0.0)$ & 1.00 \\
\hline Pulmonary embolus & $1(0.2)$ & $0(0.0)$ & $1(1.2)$ & $0(0.0)$ & .20 \\
\hline Pneumothorax & $1(0.2)$ & $1(0.4)$ & $0(0.0)$ & $0(0.0)$ & 1.00 \\
\hline Initial ventilation support $>48 \mathrm{~h}$ & $1(0.2)$ & $1(0.4)$ & $0(0.0)$ & $0(0.0)$ & 1.00 \\
\hline DVT requiring treatment & $1(0.2)$ & $1(0.4)$ & $0(0.0)$ & $0(0.0)$ & 1.00 \\
\hline Ileus & $1(0.2)$ & $1(0.4)$ & $0(0.0)$ & $0(0.0)$ & 1.00 \\
\hline Length of stay $(\mathrm{d})$, mean $( \pm \mathrm{SD})$ & $1.5( \pm 1.5)$ & $1.8( \pm 1.4)$ & $1.3( \pm 0.7)$ & $1.1( \pm 2.0)$ & $<.001$ \\
\hline Opioid prescription after surgery & $286(69.1)$ & $208(87.0)$ & $69(85.2)$ & $9(9.6)$ & $<.001$ \\
\hline Readmission within $30 \mathrm{~d}$ & $19(4.6)$ & $12(5.0)$ & $5(6.2)$ & $2(2.1)$ & .42 \\
\hline Mortality within $30 \mathrm{~d}$ & $0(0)$ & $0(0)$ & $0(0)$ & $0(0)$ & NA \\
\hline
\end{tabular}

Values are in frequency and proportion unless otherwise indicated. Differences across groups were compared using the chi-square or Fisher-Freeman-Halton exact test (for comparisons that have cell counts $<5$ ) for categoric variables and unpaired $t$ test or Kruskal-Wallis test for continuous variables as appropriate. Other than the "opioid prescription after surgery," comparisons across groups of other variables were conducted using the Fisher-Freeman-Halton exact tests. ERAS, Enhanced recovery after surgery; $I Q R$, interquartile range; $I C U$, intensive care unit; $I V$, intravenous; $G I$, gastrointestinal; $D V T$, deep vein thrombosis; $S D$, standard deviation; $N A$, not available.

discharge is subjectively decided by the surgeon on the basis of an estimation of how much pain the patient is having at the time of discharge and a predication of the severity and duration of the patient's pain during recovery. There is a wide variation of opioid prescription patterns, and most patients appear to be overprescribed opioids after surgery. ${ }^{15}$ We found there were similar levels of opioid discharge prescriptions before and after the implementation of the ERAS program at our institution; however, we also found an increase in the number of patients who stated that they never filled the prescribed opioid medication or who reported that they took 1 or 2 pills and stopped. This trend in our patients is in line with published studies suggesting that approximately $70 \%$ of the opioids prescribed after surgery are never used by patients to whom they are prescribed. ${ }^{16-18}$ This also argues for our inability, as clinicians, to accurately predict the amount of opioids the patient will need during recovery.

This feedback gathered from patients during the implementation of our ERAS program prompted us to a change how we prescribe opioid medications at the time of discharge and the development of the preemptive pain-management program. The primary objective of the program was to completely revamp our approach to discharge pain medication; rather than going home with an opioid prescription by default, patients would be discharged on nonopioid mediations around the clock. All patients received preoperative counseling about the program, preemptive pain medication in the preoperative holding area, and perioperative preemptive pain control while in the hospital. We continued the preemptive pain regimen at home upon discharge. Instead of asking for medication after they acutely have pain, patients take scheduled medications to prevent pain before it happens. An additional benefit is that patients have minimal pain the morning after surgery, thus allowing for a more seamless discharge process. Other studies have shown that if patients do not require opioids before discharge, they will have minimal opioid requirements at home. ${ }^{19}$ In our practice, this change was associated with a significant difference in the number of patients 
TABLE 4. Multivariable logistic regression for opioid prescriptions after surgery

\begin{tabular}{lcc}
\hline & Adjusted OR $(\mathbf{9 5} \% \mathbf{C I})$ & $\boldsymbol{P}$ value \\
\hline Pain control & (reference) & \\
Control & $0.73(0.34-1.57)$ & .43 \\
ERAS & $0.01(0.01-0.03)$ & $<.001$ \\
Preemptive pain & $2.85(0.79-10.27)$ & .11 \\
Opioid before surgery & $1.61(0.84-3.09)$ & .15 \\
Male gender & & \\
Surgeon & $0.37(0.09-1.49)$ & .16 \\
Surgeon 1 & $1.34(0.47-3.76)$ & .58 \\
Surgeon 2 & $1.60(0.37-6.92)$ & .53 \\
Surgeon 3 & (reference) & \\
Surgeon 4 &
\end{tabular}

Area under the curve $=0.86 . O R$, Odds ratio; $C I$, confidence interval; $E R A S$, enhanced recovery after surgery.

discharged with opioid prescriptions. Patients were instructed to call our office if the acetaminophen or naproxen was not enough for adequate pain control. In this cohort, none of the patients discharged on nonopioid medication called to request stronger medication. At 30 days after surgery, a subset of patients had minimal pain based on a selfreported pain score.

One of the surprising findings of our study was that chronic pain medications before surgery was not a factor in discharging the patient home with opioids. This may be due to the fact that patients who were on chronic pain medications were asked to discuss postoperative pain medications with their prescribing pain physician before surgery. This change was associated with fewer duplicate and redundant narcotic prescriptions.

TABLE 5. Multivariable logistic regression for postoperative complications

\begin{tabular}{lcc}
\hline & Adjusted OR $(\mathbf{9 5} \% \mathbf{C I})$ & $\boldsymbol{P}$ value \\
\hline Pain control & (reference) & \\
$\quad$ Control & $1.26(0.58-2.72)$ & .56 \\
ERAS & $0.22(0.06-0.79)$ & .02 \\
$\quad$ Preemptive pain & $1.03(1.00-1.05)$ & .07 \\
Age at time of surgery (y) & $1.53(0.78-2.99)$ & .22 \\
Male gender & & \\
ASA classification & $($ reference) & \\
II & $1.79(0.77-4.16)$ & .17 \\
III & $3.36(1.01-11.19)$ & .049 \\
IV & $1.00(1.00-1.01)$ & .27 \\
Procedure time (min) & & \\
Surgeon & $0.72(0.10-5.13)$ & .75 \\
Surgeon 1 & $1.05(0.31-3.59)$ & .94 \\
Surgeon 2 & $1.66(0.40-6.78)$ & .48 \\
Surgeon 3 & (reference) & \\
$\quad$ Surgeon 4 & & \\
\hline
\end{tabular}

Area under the curve $=0.86$. OR, Odds ratio; $C I$, confidence interval; $E R A S$, enhanced recovery after surgery; $A S A$, American Society of Anesthesiologists.
We also found that the preemptive pain control protocol along with ERAS was associated with decreased postoperative complications. To our surprise, ERAS alone did not show a significant decrease in postoperative complications. One potential explanation is that preemptive pain management with ERAS represents a maturation of our ERAS program, whereas the ERAS-alone time period represents the initial steps needed to implement the program. After creating the program, we took steps to disseminate the details to our entire team, including all involved surgeons, advanced practice providers, surgical house staff, anesthesiologists, operating room personnel, and nursing staff. Despite repeated efforts at education during the roll-out phase, consistent application was challenging and required frequent repetition and re-education for the team. Common problems included missed scheduled medication doses due to patient or staff noncompliance and inconsistent orders placed by our team. By the start of the preemptive paincontrol program, the entire thoracic team was well versed in the principles of the ERAS program. The improvement seen after starting the preemptive pain control with ERAS may be due to the full-scale implementation and adoption of the program rather than just the impact of the addition of the preemptive pain-management program. It may be the culmination of all of these factors that is associated with a significant decrease in morbidity and hospital length of stay seen in the preemptive pain-management group.

In addition, this study highlights the relationship of opioids with postoperative morbidity. The most common postoperative complications in our cohort were potentially due to known side effects of opioid use, such as urinary retention, discharge with a Foley catheter, pulmonary events, and gastrointestinal events. ${ }^{20-22}$ The preemptive pain control strategy with ERAS was associated with a significant decrease in opioid use and a decrease in complications, which resulted in decreased length of stay and improved outcomes at our institution. There are many other programs that have sent patients home the same day after minimally invasive benign foregut surgery ${ }^{23-25}$; however, the most common reasons for readmission are pain and dysphagia, and none of the studies address whether patients were able to be discharged home without opioid pain medication. Our preemptive pain-management program with the ERAS subgroup was associated with a significant decrease in length of stay with excellent pain control without opioid prescription.

\section{Study Limitations}

The study's main limitation was that it was not a randomized controlled trial. However, our study shows the evolution of a program designed with the goal of improving patient outcomes. In addition, the sample size of each group is small, but the study is adequately powered to show the impact of the program on opioid reduction and 
decrease in morbidity. Moreover, we wanted to test a standardized program that was easy to follow for patients and providers. In our study, we were able to conclude that this method of pain management for our group of patients was associated with a significant decrease in narcotic use and improved patient outcomes.

\section{CONCLUSIONS}

Our preemptive pain-control program allows patients to recover from elective foregut surgery with minimal opioids and facilitates their discharge home without opioids. The adoption and implementation of this program across multiple disciplines could result in a significant decrease in the availability of opioids in the community, which could lead to a decrease in opioid-related deaths.

\section{Conflict of Interest Statement}

Dr Kim has taught courses for Olympus, Boston Scientific, Intuitive Surgical, Veran, and Medtronic. Dr Chan has taught courses for Olympus, Boston Scientific, Veran, and Medtronic. All other authors have nothing to disclose with regard to commercial support.

The authors thank Ann Saikin for language editing of the article and Kathryn J. Schulze and Debra Selig-Rosen for providing the data collected for the Society of Thoracic Surgery at Houston Methodist Hospital.

\section{References}

1. Seth P, Rudd RA, Noonan RK, Haegerich TM. Quantifying the epidemic of prescription opioid overdose deaths. Am J Public Health. 2018;108:500-2.

2. Clarke H, Soneji N, Ko DT, Yun L, Wijeysundera DN. Rates and risk factors for prolonged opioid use after major surgery: population based cohort study. BMJ. 2014;348:g1251.

3. Alam A, Gomes T, Zheng H, Mamdani MM, Juurlink DN, Bell CM. Long-term analgesic use after low-risk surgery: a retrospective cohort study. Arch Intern Med. 2012;172:425-30.

4. Sun EC, Darnall BD, Baker LC, Mackey S. Incidence of and risk factors for chronic opioid use among opioid-naive patients in the postoperative period. JAMA Intern Med. 2016:176:1286-93.

5. Brown JK, Singh K, Dumitru R, Chan E, Kim MP. The benefits of enhanced recovery after surgery programs and their application in cardiothoracic surgery. Methodist Debakey Cardiovasc J. 2018;14:77-88.

6. Kim MP, Chan EY, Meisenbach LM, Dumitru R, Brown JK, Masud FN. Enhanced recovery after thoracic surgery reduces discharge on highly dependent narcotics. J Thorac Dis. 2018;10:984-90.

7. Brandal D, Keller MS, Lee C, Grogan T, Fujimoto Y, Gricourt Y, et al. Impact of enhanced recovery after surgery and opioid-free anesthesia on opioid prescriptions at discharge from the hospital: a historical-prospective study. Anesth Analg. 2017; 125:1784-92.

8. Newhook TE, Vreeland TJ, Dewhurst WL, Wang X, Prakash L, Feng C, et al. Clinical factors associated with practice variation in discharge opioid prescriptions after pancreatectomy. Ann Surg. November 29, 2018 [Epub ahead of print].

9. Colton IB, Fujii MH, Ahern TP, MacLean CD, Lahiri JE, Alef M, et al. Postoperative opioid prescribing patterns and use after vascular surgery. Vasc Med. 2019;24:63-9.

10. Solouki S, Plummer M, Agalliu I, Abraham N. Opioid prescribing practices and medication use following urogynecological surgery. Neurourol Urodyn. 2019;38: 363-8.

11. Howard R, Fry B, Gunaseelan V, Lee J, Waljee J, Brummett C, et al. Association of opioid prescribing with opioid consumption after surgery in Michigan. JAMA Surg. 2019;154:e184234.

12. Kissin I. Preemptive analgesia. Anesthesiology. 2000;93:1138-43.
13. Liu VX, Rosas E, Hwang J, Cain E, Foss-Durant A, Clopp M, et al Enhanced recovery after surgery program implementation in 2 surgical populations in an integrated health care delivery system. JAMA Surg. 2017;152:e171032.

14. Li Z, Zhao Q, Bai B, Ji G, Liu Y. Enhanced recovery after surgery programs for laparoscopic abdominal surgery: a systematic review and meta-analysis. World $J$ Surg. 2018;42:3463-73.

15. Thiels CA, Anderson SS, Ubl DS, Hanson KT, Bergquist WJ, Gray RJ, et al. Wide variation and overprescription of opioids after elective surgery. Ann Surg. 2017;266:564-73.

16. Feinberg AE, Chesney TR, Srikandarajah S, Acuna SA, McLeod RS, Best Practice in Surgery Group. Opioid use after discharge in postoperative patients: a systematic review. Ann Surg. 2018;267:1056-62.

17. Hill MV, McMahon ML, Stucke RS, Barth RJ Jr. Wide variation and excessive dosage of opioid prescriptions for common general surgical procedures. Ann Surg. 2017;265:709-14.

18. Howard R, Waljee J, Brummett C, Englesbe M, Lee J. Reduction in opioid prescribing through evidence-based prescribing guidelines. JAMA Surg. 2018;153: 285-7.

19. Hill MV, Stucke RS, Billmeier SE, Kelly JL, Barth RJ Jr. Guideline for discharge opioid prescriptions after inpatient general surgical procedures. J Am Coll Surg. 2018:226:996-1003.

20. Sayal P, Bateman BT, Menendez M, Eikermann M, Ladha KS. Opioid use disorders and the risk of postoperative pulmonary complications. Anesth Analg. 2018; 127:767-74.

21. Lee LA, Caplan RA, Stephens LS, Posner KL, Terman GW, Voepel-Lewis T, et al. Postoperative opioid-induced respiratory depression: a closed claims analysis. Anesthesiology. 2015;122:659-65.

22. de Boer HD, Detriche O, Forget P. Opioid-related side effects: postoperative ileus, urinary retention, nausea and vomiting, and shivering A review of the literature. Best Pract Res Clin Anaesthesiol. 2017;31:499-504.

23. Mistry P, Zaman S, Shapey I, Daskalakis M, Nijjar R, Richardson M, et al. Build ing a model for day case hiatal surgery - lessons learnt over a 10 year period in a high volume unit: a case series. Int J Surg. 2018;54:82-5.

24. Agrawal S, Shapey I, Peacock A, Ali A, Super P. Prospective study of routine day-case laparoscopic modified Lind partial fundoplication. World J Surg. 2009;33:1229-34.

25. Thomas H, Agrawal S. Systematic review of day-case laparoscopic fundoplication. J Laparoendosc Adv Surg Tech A. 2011;21:781-8.

Key Words: enhanced recovery after surgery, foregut surgery, hiatal hernia, minimally invasive surgery, opioids, preemptive pain control

\section{Discussion}

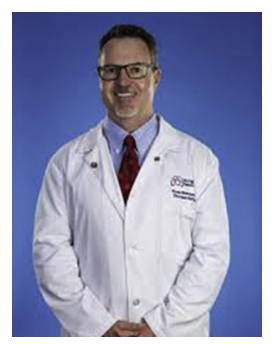

Dr Ross Bremner. So we're going to get on with the second session, and we will start with Dr Kim presenting "Preemptive Pain-Management Program Is Associated With Reduction of Opioid Prescriptions After Benign Minimally Invasive Foregut Surgery" from Houston Methodist Hospital. Dr Kim?

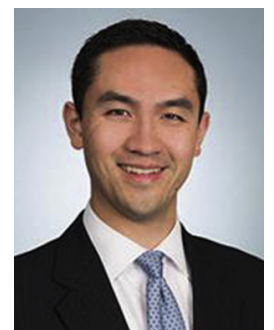

Dr Edward Y. Chan (Houston, Tex). Good morning. I'm actually Ed Chan, I'm presenting on behalf of my colleagues at Houston Methodist including Dr Kim, but Dr Bremner, Dr Cain, Dr Kim, distinguished members, and guests, as a new member of the Western Thoracic, it's my distinct honor to be invited and have the opportunity to present our work on behalf of my colleagues at Houston 
Methodist. Today will be discussing our preemptive painmanagement program and how it has resulted in a reduction in our opioid prescriptions after benign foregut surgery. The ongoing opioid epidemic needs little introduction, but the numbers continue to be jarring. Prescription opioids lead to more than 17,000 deaths in 2016. A major contributor to the problem is the widespread availability of opioid medications prescribed after elective surgery. Up to $10 \%$ of patients who are opioid naive going into surgery will continue to take opioids at 1 year after their surgical procedure. In the literature, predominantly from the colorectal experience, the adoption of an enhanced recovery or ERAS program has not been successful in reducing the number of opioids prescribed after surgery. The same was true at our institution. Although our ERAS program limited the number of opioids administered postoperatively in-house, there was no significant reduction in the number of opioids or the number of prescriptions that patients were being sent home with and therefore bringing back into the community. So we attempted to change the culture at our institution by creating a preemptive pain-control program with the goal being to incorporate the ERAS protocol and what we had achieved with that and leverage it into discharging fewer patients with opioids. Obviously, we would not have been satisfied sending patients home with fewer opioids if it meant inferior or inadequate pain control, but we had seen that while they were in-house, they had required fewer opioids and so we hypothesized that these patients would be able to be sent home without prescription opioids. We evaluated that by giving them a survey of their self-reported pain levels at their postoperative visit 30 days afterward. So creation of this preemptive pain-control program consists of both a patient and a provider component. On the patient side, we would have to explain to the patients that instead of waiting for them to have pain postoperatively and treating it as needed often with opioids, we would incorporate non-narcotic pain medications around the clock, which would allow us to try to stay ahead of their pain. We would also try to align their expectations so that they knew that most patients were able to be successfully discharged home without narcotics. From a provider standpoint, we had to ensure that our entire team of thoracic surgeons, position assistants, nurse practitioners, and General Surgery residents were all on board with discharging patients home without narcotics by default, as our default setting. We have previously described our ERAS protocol and it is probably similar to a lot of what you are doing at your institutions, but key elements include intraoperative administration of long-acting local anesthetics such as bupivacaine (Exparel; Pacira Biosciences Inc, Parsippany, NJ), the use of IV acetaminophen (Tylenol; McNeil Consumer Healthcare, Fort Washington, $\mathrm{Pa}$ ) and IV ketorolac (Toradol; Cycle Pharmaceuticals
Ltd, Cambridge, United Kingdom) during the operation, and then after surgery we would administer IV Tylenol and IV Toradol around the clock at least into the first postoperative day. Part of the reasoning for that was we wanted to try to minimize the number of instances in which patients declined to get their medication as scheduled because it was inconvenient or the wrong time, so that by giving it IV, we sort of circumvented that. If those were inadequate for pain control, we added gabapentin, cyclobenzaprine, or tramadol in that order as needed. And finally, if that was still inadequate, we would add IV pushes of hydromorphone or hydromorphone patient-controlled analgesia if needed. On discharge home, patients would be instructed to take nonsteroidal anti-inflammatory drugs as scheduled for 3 days and Tylenol is scheduled for 5 days, each around the clock and to call our office if they needed a prescription for something stronger or if that was not adequately controlling their pain. So we performed a retrospective analysis of prospectively collected data that was part of our Society of Thoracic Surgeons data reporting for all benign foregut surgery performed by the surgeons in our division from 2012 to 2018. We also reviewed the type of pain medication that each patient was discharged home with, and once we had started the preemptive pain-control regimen, we started administering the self-reported pain questionnaire at their postoperative visit.

Just a timeline of how long it took us to do these things, we started in 2014 implementing some of the aspects of our ERAS protocol and it wasn't really until 2016 that we were able to fully implement it and get full buy-in from Anesthesia, Nursing, and the Surgical teams. Following that in 2017, we began this preemptive pain management protocol. We had a total of 414 patients in the cohort. The average age is 60 years old. They had fairly mild comorbidities. The cohort before the initiation of the preemptive pain management group was 320 patients who were used as a control and 94 patients in the study group. We see that between groups, we have a higher percentage of patients who are on opioids before surgery and with a preemptive pain group relatively more patients with a hiatal hernia versus gastroesophageal reflux disease as a diagnosis, and then by the time we had implemented our preoperative pain regimen, we had made the jump to doing $100 \%$ of these operations robotically with the da Vinci XI system (Intuitive, Sunnyvale, Calif).

Our results show that we were able to decrease the number of patients who were discharged home with opioids to $10 \%$ from $86 \%$ beforehand. At the same time, our length of stay in this group decreased to 1.1 days postoperatively from 1.6 days, which is statistically significant as well. Our postoperative complications per Society of Thoracic Surgeons criteria decreased to $3 \%$ in the study group from $15 \%$, and there were only 3 patients in this group that had complications. Two of them had urinary retention, and 1 had a 
superficial surgical site infection. We performed univariable and multivariable logistic regression for factors that contributed to opioid prescription at discharge, and the preemptive pain control was a significant factor. Somewhat surprisingly, patients being on opioids before surgery actually did not turn out to be statistically significant in predicting their discharge with opioids. We performed the same analysis for factors contributing to postoperative complications and again found that the preemptive pain control was a significant factor in decreasing those complications. Having an ASA classification of IV trended toward being a significant risk factor for having complications but was not quite significant. This is a questionnaire that we gave to the patients to self-report their pain score afterward. It asks them what pain medication they are taking after surgery and before surgery. At the bottom, there is a Likert scale asking them to rate their pain levels postoperatively at 30 days from 0 to 10 with 0 being the least and 10 being the most, and 55 of our 94 patients filled this out. Their mean self-reported pain score was 0.7 among that cohort. Limitations to our article include that it is, you know, those inherent with having a retrospective study. We are unable to say that this is the sole reason for our improved results, but we think that there are certainly other factors that may have played into this that are not measurable. Also having it be a single institution is a limitation as well.

In conclusion, we offer that this preemptive pain management program can lead to an opioid-free discharge after benign foregut surgery. We believe it can lead to shorter length of stay and fewer complications. Importantly, we see that it is effective with a low self-reported pain level at 30 days after surgery. I will be happy to take any questions.

Dr Bremner. We will open the discussion with Dr Anthony Kim.

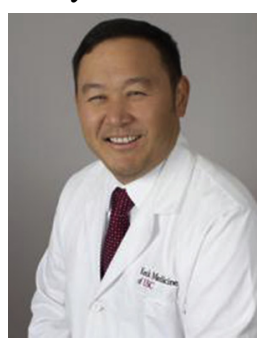

Dr Anthony Kim. Dr Bremner, Dr Cain, members, and guests, I would like to thank the program committee from the Western for the opportunity to discuss this very important article. I would also like to thank Drs Chan, Kim, and colleagues for providing me a copy of their well-written article and slides well in advance of this meeting. In their study, the authors set out to determine the efficacy of their preemptive pain-management program and to determine the factors associated with the discharge of patients without opioid prescriptions. In their sound analysis, they identify the use of preemptive strategies as the lone determinant in the discharge of patients without opioids and the lone factor associated with the reduction in postoperative events. Among many interesting results, one of the more surprising ones was that the approach did not influence the use of opioids. I believe that this is important and underscores the importance of a multidisciplinary approach and certainly an avenue of further study. With all that said, I have 3 questions for Dr Chan and coauthors. My first question pertains to how the authors defined preexisting ERAS protocols. Many protocols already include preemptive preoperative nonopioid medications as a component of a true multidisciplinary approach. Therefore, can the authors clarify what they were what they were calling ERAS pathways and how that was different then a fast tracking protocol? Your article hints at this, but I just wanted to gain greater clarity. The second question I had was that pertains to, at our institution we have found that but not so insignificant determinant of who gets pain medications is our nurses. We have tried to limit this variability through developing order sets that limits what can be given when there is a subjective interpretation of pain, and we have relied upon teaching and didactics to instruct our nursing colleagues how to manage pain an what to expect with specific types of operations. Can you speak to this issue, and then finally, my personal belief is that patients using opiates before surgery represent a different cohort of patients unique from the opioid-naive group. I think you had, in your last slide that was subsequently removed in the version you had before, you showed that a percentage of patients using opioids after surgery was higher in those patients who had opiates before surgery, but that same group didn't get opiate prescriptions. So how do you counsel that group of preoperative opioid users?

Dr Chan. So to the first question, in terms of how we differentiate the preemptive pain-control regimen from our ERAS protocol, I think there's not really necessarily standardization for what ERAS entails. For our own institution, our ERAS protocol that we tried to initiate at first, you know, that includes preoperative pain control, intraoperative factors, and anesthesia factors, it didn't really focus on the discharge home without opioids. We did, I think, so many of us have been used to, I am not that far out of residency, but in residency, you know, everyone who got a lap chole would go home with 50 Norco and it was just very normal, and I think that...that sort of mentality was one of the biggest barriers to try to change to get to this point, and we hadn't explicitly defined it as part of our ERAS protocol before. This is sort of taking that final step, but certainly if you can incorporate it into the initiation of ERAS protocol I think that's only to your benefit. Your second question about educating at the whole team including nursing staff I think is a very good one. Part of the reason we order the IV pain medicine to be given around the clock the first 12 to 24 hours is to try to avoid that variability because a lot of times if a patient is due for their pain medication at 2:00 $\mathrm{AM}$, they're going to refuse it with a nurse refusing to give it or something along that line, so we try to take that variability out of it by making it IV until the next morning when they would be awake and could take it by mouth, so I think certainly education is an important part of it, and we do the same thing you were describing 
in terms of in services and trying to get everyone on board but as you see from the timeline. That's why it took us 2 to 3 years to really implement it all the way because it takes a lot of repetition and oversight to make sure it works okay. As for your last point, which I think is a very good one in terms of patients who come in on narcotics being very different in terms of their pain sensitivity and their ability to go home without narcotics, we have been more aggressive recently in trying to get them off their narcotics beforehand and we will send them to their pain doctor or primary care doctor who is giving them the medication and try to have them off their pain medication entirely for about 30 days before. If not, we have a low threshold for giving them the same pain medication that they were on before or having them go back to the same prescribing physician. That way we don't confound factors and have multiple prescribers prescribing opioids, but we certainly try our best to get them off their pain medicine before they come into surgery.

Speaker. Dr Chan, I really like this study because it's all about setting expectations. You tell the patients what to expect, they actually translate amazingly and had better outcomes because of that, less have pain at 30 days, and when you have no complications you are actually saving money and they discharge faster. So it's really a great thing to do. I think it could be translated to adult heart surgery and other forms of general surgery, I'm sure it is. Ross has a question.

Dr Chan. I appreciate that. Oh, I'm sorry.

Dr Bremner. We've got 2 minutes.
Dr Chan. Sure.

Dr Bremner. You know, you called this preemptive analgesia, but really, you're starting a lot of this stuff at the time of the surgery. Is there, apart from the educational aspects, is there anything else that you and your anesthesiologists are doing before incision? For example, administering the ketorolac in the holding area preoperatively, local anesthesia before incision, and then using local anesthesia to douse the diaphragm at the end of the operation, presuming if you're doing it laparoscopically or robotically?

Dr Chan. Excellent question. To your point, Dr Cain, I think that when we talk to patients about it in the clinic beforehand, they are all for it. You know, patients these days don't want to be on narcotics for the most part, and when they do, that's sort of a red flag already. These patients really like the fact that we're not putting them on narcotics so they are very much on-board with the plan beforehand, and I think that as part of our ERAS protocol, we give them gabapentin in the preoperative area, we give, depending on the patient, we give most of them a dose of Toradol also, and then, a lot of what the anesthesiologists are doing intraoperatively, with their induction as well as during the operation also helps. They are not giving narcotics during the operation, they are even using total IV anesthesia, minimizing fluids, all those things really play a role in priming the patient for success after the surgery. 
TABLE E1. Univariable logistic regression of characteristics associated with opioid prescription after surgery

\begin{tabular}{|c|c|c|c|c|}
\hline \multirow[b]{2}{*}{ Characteristics } & \multicolumn{2}{|c|}{ Opioid prescription after surgery } & \multirow[b]{2}{*}{$\frac{\text { Unadjusted OR }}{(95 \% \mathbf{C I})}$} & \multirow[b]{2}{*}{$P$ value } \\
\hline & $\begin{array}{c}\text { No } \\
(n=128)\end{array}$ & $\begin{array}{c}\text { Yes } \\
(n=286)\end{array}$ & & \\
\hline \multicolumn{5}{|l|}{ Pain control } \\
\hline Control & $31(24.2)$ & $208(72.7)$ & (reference) & \\
\hline ERAS & $12(9.4)$ & $69(24.1)$ & $0.86(0.42-1.76)$ & .67 \\
\hline Preemptive pain & $85(66.4)$ & $9(3.1)$ & $0.02(0.01-0.03)$ & $<.001$ \\
\hline Age (y) & $62.0(53.0-72.5)$ & $60.0(49.0-71.0)$ & $1.00(0.98-1.01)$ & .57 \\
\hline \multicolumn{5}{|l|}{ Gender } \\
\hline Female & $91(71.1)$ & 177 (61.9) & (reference) & \\
\hline Male & $37(28.9)$ & $109(38.1)$ & $1.51(0.97-2.38)$ & .07 \\
\hline \multicolumn{5}{|l|}{ White } \\
\hline Non-white & $21(16.4)$ & $58(20.3)$ & (reference) & \\
\hline White & $107(83.6)$ & $228(79.7)$ & $0.77(0.45-1.34)$ & .36 \\
\hline Body mass index, median (IQR) & $28.8(25.0-33.5)$ & $29.1(25.8-33.1)$ & $1.00(0.96-1.03)$ & .80 \\
\hline \multicolumn{5}{|l|}{ Hypertension } \\
\hline No & $61(47.7)$ & $127(44.4)$ & (reference) & \\
\hline Yes & $67(52.3)$ & $159(55.6)$ & $1.14(0.75-1.73)$ & .54 \\
\hline \multicolumn{5}{|l|}{ Steroids } \\
\hline No & $125(97.7)$ & $283(99.0)$ & (reference) & \\
\hline Yes & $3(2.3)$ & $3(1.0)$ & $0.44(0.06-3.35)$ & .54 \\
\hline \multicolumn{5}{|l|}{ Congestive heart failure } \\
\hline No & $127(99.2)$ & $284(99.3)$ & (reference) & \\
\hline Yes & $1(0.8)$ & $2(0.7)$ & $0.89(0.05-53.18)$ & 1.00 \\
\hline \multicolumn{5}{|l|}{ Coronary artery disease } \\
\hline No & $111(86.7)$ & $253(88.5)$ & (reference) & \\
\hline Yes & $17(13.3)$ & $33(11.5)$ & $0.85(0.46-1.59)$ & .62 \\
\hline \multicolumn{5}{|l|}{ Peripheral vascular disease } \\
\hline No & $125(97.7)$ & $283(99.0)$ & (reference) & \\
\hline Yes & $3(2.3)$ & $3(1.0)$ & $0.44(0.06-3.35)$ & .54 \\
\hline \multicolumn{5}{|l|}{ Prior cardiothoracic surgery } \\
\hline No & $122(95.3)$ & $270(94.4)$ & (reference) & \\
\hline Yes & $6(4.7)$ & $16(5.6)$ & $1.20(0.46-3.15)$ & .70 \\
\hline \multicolumn{5}{|l|}{ Cerebrovascular history } \\
\hline No & $118(92.2)$ & $270(94.4)$ & (reference) & \\
\hline Yes & $10(7.8)$ & $16(5.6)$ & $0.70(0.31-1.59)$ & .39 \\
\hline \multicolumn{5}{|l|}{ Pulmonary hypertension } \\
\hline No & $128(100.0)$ & $283(99.0)$ & NA & \\
\hline Yes & $0(0.0)$ & $3(1.0)$ & & \\
\hline \multicolumn{5}{|l|}{ Diabetes } \\
\hline No & $113(88.3)$ & $247(86.4)$ & (reference) & \\
\hline Yes & $15(11.7)$ & $39(13.6)$ & $1.19(0.63-2.25)$ & .59 \\
\hline \multicolumn{5}{|l|}{ Currently on dialysis } \\
\hline No & $127(99.2)$ & $285(99.7)$ & (reference) & \\
\hline Yes & $1(0.8)$ & $1(0.3)$ & $0.45(0.01-35.25)$ & 1.00 \\
\hline \multicolumn{5}{|l|}{ COPD } \\
\hline No & $118(92.2)$ & 257 (89.9) & (reference) & \\
\hline Yes & $10(7.8)$ & $29(10.1)$ & $1.33(0.63-2.82)$ & .46 \\
\hline \multicolumn{5}{|l|}{ Interstitial fibrosis } \\
\hline No & $126(98.4)$ & $282(98.6)$ & (reference) & \\
\hline Yes & $2(1.6)$ & $4(1.4)$ & $0.89(0.16-4.94)$ & .90 \\
\hline Last creatinine level, median (IQR) & $0.9(0.7-1.1)$ & $0.8(0.7-1.0)$ & $0.99(0.64-1.53)$ & .95 \\
\hline
\end{tabular}




\begin{tabular}{|c|c|c|c|c|}
\hline \multirow[b]{2}{*}{ Characteristics } & \multicolumn{2}{|c|}{ Opioid prescription after surgery } & \multirow[b]{2}{*}{$\frac{\text { Unadjusted OR }}{(95 \% \mathrm{CI})}$} & \multirow[b]{2}{*}{$P$ value } \\
\hline & $\begin{array}{c}\text { No } \\
(n=128)\end{array}$ & $\begin{array}{c}\text { Yes } \\
(n=286)\end{array}$ & & \\
\hline Last hemoglobin level, median (IQR) & $13.4(12.4-14.6)$ & $13.3(12.1-14.3)$ & $0.95(0.84-1.06)$ & .34 \\
\hline \multicolumn{5}{|l|}{ ASA classification } \\
\hline II & $54(42.2)$ & $111(38.8)$ & (reference) & \\
\hline III & $64(50.0)$ & $149(52.1)$ & $1.13(0.73-1.75)$ & .58 \\
\hline IV & $10(7.8)$ & $26(9.1)$ & $1.26(0.57-2.81)$ & .56 \\
\hline \multicolumn{5}{|l|}{ Cigarette smoking } \\
\hline Never smoked & $93(72.7)$ & $187(65.4)$ & (reference) & \\
\hline Past or current smoker & $35(27.3)$ & 99 (34.6) & $1.41(0.89-2.23)$ & .15 \\
\hline \multicolumn{5}{|l|}{ Zubrod score } \\
\hline 1 & $5(3.9)$ & $13(4.5)$ & (reference) & \\
\hline 2 & $116(90.6)$ & $257(89.9)$ & $0.85(0.30-2.45)$ & .77 \\
\hline 3 & $1(0.8)$ & $4(1.4)$ & $1.54(0.14-17.33)$ & .73 \\
\hline 4 & $6(4.7)$ & $12(4.2)$ & $0.77(0.19-3.19)$ & .72 \\
\hline \multicolumn{5}{|l|}{ Primary procedure } \\
\hline Fundoplication & $8(6.3)$ & $38(13.3)$ & $2.30(1.04-5.08)$ & .04 \\
\hline Heller myotomy & $22(17.2)$ & $49(17.1)$ & $1.00(0.57-1.73)$ & .99 \\
\hline Hiatal hernia repair without mesh & $97(75.8)$ & $193(67.5)$ & $0.66(0.41-1.07)$ & .09 \\
\hline Hiatal hernia repair with mesh & $1(0.8)$ & $6(2.1)$ & $2.72(0.32-22.84)$ & .36 \\
\hline \multicolumn{5}{|l|}{ Disease } \\
\hline GERD & $8(6.3)$ & $38(13.3)$ & (reference) & \\
\hline Achalasia & $22(17.2)$ & $49(17.1)$ & $0.47(0.19-1.17)$ & .10 \\
\hline Hiatal hernia & $98(76.6)$ & $199(69.6)$ & $0.43(0.19-0.95)$ & .04 \\
\hline \multicolumn{5}{|l|}{ Opioid before surgery } \\
\hline No & $117(91.4)$ & $265(92.7)$ & (reference) & \\
\hline Yes & $11(8.6)$ & $21(7.3)$ & $0.84(0.39-1.80)$ & .66 \\
\hline \multicolumn{5}{|l|}{ Robotic technology assisted } \\
\hline No & $29(22.7)$ & $175(61.2)$ & (reference) & \\
\hline Yes & $99(77.3)$ & $111(38.8)$ & $0.19(0.12-0.30)$ & $<.001$ \\
\hline \multicolumn{5}{|l|}{ Reoperation } \\
\hline No & $107(83.6)$ & $251(87.8)$ & (reference) & \\
\hline Yes & $21(16.4)$ & $35(12.2)$ & $0.71(0.40-1.28)$ & .25 \\
\hline \multicolumn{5}{|c|}{ Unanticipated surgical approach conversion } \\
\hline No & $127(99.2)$ & $286(100.0)$ & NA & \\
\hline Yes & $1(0.8)$ & $0(0.0)$ & & \\
\hline Procedure time (min), median (IQR) & $174.0(148.0-209.0)$ & $171.0(138.0-209.0)$ & $1.00(1.00-1.00)$ & .17 \\
\hline \multicolumn{5}{|l|}{ Surgeon } \\
\hline Surgeon 1 & $7(5.5)$ & $16(5.6)$ & $3.63(1.24-10.64)$ & .02 \\
\hline Surgeon 2 & $90(70.3)$ & $214(74.8)$ & $3.78(1.96-7.27)$ & $<.001$ \\
\hline Surgeon 3 & $4(3.1)$ & $39(13.6)$ & $15.49(4.69-51.14)$ & $<.001$ \\
\hline Surgeon 4 & $27(21.1)$ & $17(5.9)$ & (reference) & \\
\hline
\end{tabular}

Values are in frequency and \% unless otherwise indicated. $O R$, Odds ratio; $C I$, confidence interval; $E R A S$, enhanced recovery after surgery; IQR, interquartile range; $N A$, not available; COPD, chronic obstructive pulmonary disease; $A S A$, American Society of Anesthesiologists; GERD, gastroesophageal reflux disease. 
TABLE E2. Univariable logistic regression of characteristics associated with opioid prescription after surgery

\begin{tabular}{|c|c|c|c|c|}
\hline Characteristics & $\frac{\text { No postoperative event }}{(n=363)}$ & $\frac{\text { Postoperative event }}{(\mathrm{n}=\mathbf{5 1})}$ & $\frac{\text { Unadjusted OR }}{(95 \% \mathbf{C I})}$ & $P$ value \\
\hline \multicolumn{5}{|l|}{ Pain control } \\
\hline Control & $203(55.9)$ & $36(70.6)$ & (reference) & \\
\hline ERAS & $69(19.0)$ & $12(23.5)$ & $0.98(0.48-1.99)$ & .96 \\
\hline Preemptive pain & $91(25.1)$ & $3(5.9)$ & $0.19(0.06-0.62)$ & .01 \\
\hline Age (y) & $59.0(49.0-70.0)$ & $71.0(55.0-77.0)$ & $1.04(1.01-1.06)$ & .001 \\
\hline \multicolumn{5}{|l|}{ Gender } \\
\hline Female & $238(65.6)$ & $30(58.8)$ & (reference) & \\
\hline Male & $125(34.4)$ & $21(41.2)$ & $1.33(0.73-2.42)$ & .35 \\
\hline \multicolumn{5}{|l|}{ White } \\
\hline Non-white & 65 (17.9) & $14(27.5)$ & (reference) & \\
\hline White & $298(82.1)$ & $37(72.5)$ & $0.58(0.29-1.13)$ & .11 \\
\hline Body mass index, median (IQR) & $29.1(25.7-33.3)$ & $28.2(24.5-31.9)$ & $0.95(0.90-1.00)$ & .048 \\
\hline \multicolumn{5}{|l|}{ Hypertension } \\
\hline No & $173(47.7)$ & $15(29.4)$ & (reference) & \\
\hline Yes & $190(52.3)$ & $36(70.6)$ & $2.19(1.16-4.13)$ & .02 \\
\hline \multicolumn{5}{|l|}{ Steroids } \\
\hline No & $357(98.3)$ & $51(100.0)$ & (reference) & \\
\hline Yes & $6(1.7)$ & $0(0.0)$ & $0.86(0.00-6.12)$ & .90 \\
\hline \multicolumn{5}{|l|}{ Congestive heart failure } \\
\hline No & $360(99.2)$ & $51(100.0)$ & (reference) & \\
\hline Yes & $3(0.8)$ & $0(0.0)$ & $1.85(0.00-17.4)$ & 1.00 \\
\hline \multicolumn{5}{|l|}{ Coronary artery disease } \\
\hline No & $325(89.5)$ & $39(76.5)$ & (reference) & \\
\hline Yes & $38(10.5)$ & $12(23.5)$ & $2.63(1.27-5.46)$ & .01 \\
\hline \multicolumn{5}{|l|}{ Peripheral vascular disease } \\
\hline No & $360(99.2)$ & $48(94.1)$ & (reference) & \\
\hline Yes & $3(0.8)$ & $3(5.9)$ & $7.43(57.11-0.00)$ & .97 \\
\hline \multicolumn{5}{|l|}{ Prior cardiothoracic surgery } \\
\hline No & $343(94.5)$ & $49(96.1)$ & (reference) & \\
\hline Yes & $20(5.5)$ & $2(3.9)$ & $0.70(0.16-3.09)$ & .64 \\
\hline \multicolumn{5}{|l|}{ Cerebrovascular history } \\
\hline No & $342(94.2)$ & $46(90.2)$ & (reference) & \\
\hline Yes & $21(5.8)$ & $5(9.8)$ & $1.77(0.64-4.92)$ & .27 \\
\hline \multicolumn{5}{|l|}{ Pulmonary hypertension } \\
\hline No & $361(99.4)$ & $50(98.0)$ & (reference) & \\
\hline Yes & $2(0.6)$ & $1(2.0)$ & $3.61(0.32-40.54)$ & .30 \\
\hline \multicolumn{5}{|l|}{ Diabetes } \\
\hline No & $318(87.6)$ & $42(82.4)$ & (reference) & \\
\hline Yes & $45(12.4)$ & 9 (17.6) & $1.51(0.69-3.32)$ & .30 \\
\hline \multicolumn{5}{|l|}{ Currently on dialysis } \\
\hline No & $362(99.7)$ & $50(98.0)$ & (reference) & \\
\hline Yes & $1(0.3)$ & $1(2.0)$ & $7.18(0.09-569.81)$ & .46 \\
\hline \multicolumn{5}{|l|}{ COPD } \\
\hline No & $330(90.9)$ & $45(88.2)$ & (reference) & \\
\hline Yes & $33(9.1)$ & $6(11.8)$ & $1.33(0.53-3.36)$ & .54 \\
\hline \multicolumn{5}{|l|}{ Interstitial fibrosis } \\
\hline No & 357 (98.3) & $51(100.0)$ & NA & \\
\hline Yes & $6(1.7)$ & $0(0.0)$ & & \\
\hline
\end{tabular}


TABLE E2. Continued

\begin{tabular}{|c|c|c|c|c|}
\hline Characteristics & $\frac{\text { No postoperative event }}{(n=363)}$ & $\frac{\text { Postoperative event }}{(n=51)}$ & $\frac{\text { Unadjusted OR }}{(95 \% \mathrm{CI})}$ & $P$ value \\
\hline Last creatinine level, median (IQR) & $0.8(0.7-1.0)$ & $0.9(0.8-1.1)$ & $1.15(0.70-1.90)$ & .58 \\
\hline Last hemoglobin level, median (IQR) & $13.4(12.3-14.3)$ & $13.1(11.5-14.6)$ & $0.88(0.76-1.03)$ & .12 \\
\hline \multicolumn{5}{|l|}{ ASA classification } \\
\hline II & $155(42.7)$ & $10(19.6)$ & (reference) & \\
\hline III & $184(50.7)$ & $29(56.9)$ & $2.44(1.15-5.17)$ & .02 \\
\hline IV & $24(6.6)$ & $12(23.5)$ & $7.75(3.02-19.90)$ & $<.001$ \\
\hline \multicolumn{5}{|l|}{ Cigarette smoking } \\
\hline Never smoked & $245(67.5)$ & $35(68.6)$ & (reference) & \\
\hline Past or current smoker & $118(32.5)$ & $16(31.4)$ & $0.95(0.51-1.78)$ & .87 \\
\hline \multicolumn{5}{|l|}{ Primary procedure } \\
\hline Fundoplication & $40(11.0)$ & $6(11.8)$ & $1.08(0.43-2.68)$ & .87 \\
\hline Heller myotomy & $63(17.4)$ & $8(15.7)$ & $0.89(0.40-1.98)$ & .77 \\
\hline Hiatal hernia repair without mesh & $253(69.7)$ & $37(72.5)$ & $1.15(0.60-2.21)$ & .68 \\
\hline Hiatal hernia repair with mesh & $7(1.9)$ & $0(0.0)$ & (reference) & \\
\hline \multicolumn{5}{|l|}{ Disease } \\
\hline GERD & $40(11.0)$ & $6(11.8)$ & (reference) & \\
\hline Achalasia & $63(17.4)$ & $8(15.7)$ & $0.85(0.27-2.62)$ & .77 \\
\hline Hiatal hernia & $260(71.6)$ & $37(72.5)$ & $0.95(0.38-2.39)$ & .91 \\
\hline \multicolumn{5}{|l|}{ Narcotics before surgery } \\
\hline No & $335(92.3)$ & $47(92.2)$ & (reference) & \\
\hline Yes & $28(7.7)$ & $4(7.8)$ & $1.02(0.34-3.03)$ & .97 \\
\hline \multicolumn{5}{|l|}{ Robotic technology assisted } \\
\hline No & $171(47.1)$ & $33(64.7)$ & (reference) & \\
\hline Yes & $192(52.9)$ & $18(35.3)$ & $0.49(0.26-0.89)$ & .02 \\
\hline \multicolumn{5}{|l|}{ Reoperation } \\
\hline No & $311(85.7)$ & $47(92.2)$ & (reference) & \\
\hline Yes & $52(14.3)$ & $4(7.8)$ & $0.51(0.18-1.47)$ & .21 \\
\hline \multicolumn{5}{|c|}{ Unanticipated surgical approach conversion } \\
\hline No & $363(100.0)$ & $50(98.0)$ & NA & \\
\hline Yes & $0(0.0)$ & $1(2.0)$ & & \\
\hline Procedure time $(\mathrm{min})$, median (IQR) & $171.0(142.0-204.0)$ & $191.0(137.0-232.0)$ & $1.00(1.00-1.01)$ & .07 \\
\hline \multicolumn{5}{|l|}{ Surgeon } \\
\hline Surgeon 1 & $21(5.8)$ & $2(3.9)$ & $0.95(0.16-5.63)$ & .96 \\
\hline Surgeon 2 & $269(74.1)$ & $35(68.6)$ & $1.30(0.44-3.86)$ & .64 \\
\hline Surgeon 3 & $33(9.1)$ & $10(19.6)$ & $3.03(0.87-10.55)$ & .08 \\
\hline Surgeon 4 & $40(11.0)$ & $4(7.8)$ & (reference) & \\
\hline
\end{tabular}

Values are in frequency and \% unless otherwise specified. $O R$, Odds ratio; $C I$, confidence interval; $E R A S$, enhanced recovery after surgery; IQR, interquartile range; $C O P D$, chronic obstructive pulmonary disease; $N A$, not available; $A S A$, American Society of Anesthesiologists; GERD, gastroesophageal reflux disease. 